\title{
sciendo
}

$10.2478 / \mathrm{msd}-2018-0009$

\section{CROSS CULTURAL KNOWLEDGE, ETHNO-CONSERVATION, AND SUSTAINABILITY PRAGMATISM}

\author{
NOSAYABA O., OKA \\ Centre for Community Empowerment and Sustainable Development (CESDEV), oka nosayaba@yahoo.com
}

\begin{abstract}
Local conservative knowledge cut across small-scale ecological natural resource management practices, whilst scientific innovations generates extensive solutions using key principles of empirical study. Assessing tribal peoples' lifestyles, disposition and the preservation of the rich cultural endowments and vegetation fertility, shows linkages of strict enforcement of customary environmentalism to secure livelihood sources. This qualitative study uses descriptive comparison of cross-cultural conservation practices to underscore the reconciliation of cultural knowledge, natural ecology sustainability. Data and case studies from cultural behaviours, perceptions and attitudes of certain tribal groups were processed and presented as strategies and solutions for inclusive propositions. Theories and dataset from previous journals, reports, books and conference communique from multilateral agencies, non-political actors, research institutes were resourceful in arriving at conclusions that will provide a common path that accentuates cultural ecological practices to broaden the campaign for sustainability.
\end{abstract}

\section{INTRODUCTION: CULTURAL DIMENSION IN ETHNO-CONSERVATION AND SUSTAINABILITY}

Culture is a fluid multi-dimensional paradigm that evolves subtly and tangibly using modes of expression to express meanings. It is interpreted differently depending on the context, reflecting the values of a people, their undertakings, lifestyles and the significances attached to things especially when confronted with certain concepts outside the social creed. Some tribal people connect by singing, dancing folklores and other rituals. But cultures are consistently shaped by the relationships of the ecological diversities where people evolve. Multiple features like customs/religion, modes of expression, social organisation, conflicts, politics/laws economics organisation, environment and technology intermingle, intra-cultural and cross-cultural structures becomes complicated. To maintain harmony, communities develop local based knowledge systems that incorporate family histories, and other elements of cultures like taboos, symbols, festivals, proverbs, literature (Kanowski and Williams, 2009). Anand (1981) underscored that cultures include peoples past history, religion, philosophy, law, interest, language and all other capabilities acquired by individuals as a member of the society. Its an indispensable intrinsically valuable social practices that have evolved historically, through the instruments of language as a means of expression. But the connection between community structures to the natural vegetation and how its past relates to its geography and practices defines its cultural system. Notwithstanding, culture cannot be reduced entirely to organic process but should be predicated on a synthesis of shared practice, relationships or foundations and configure a model for evolving its heritage through generations as articulated in figure 1. 
Figure 1. Cultural Evolvement Model

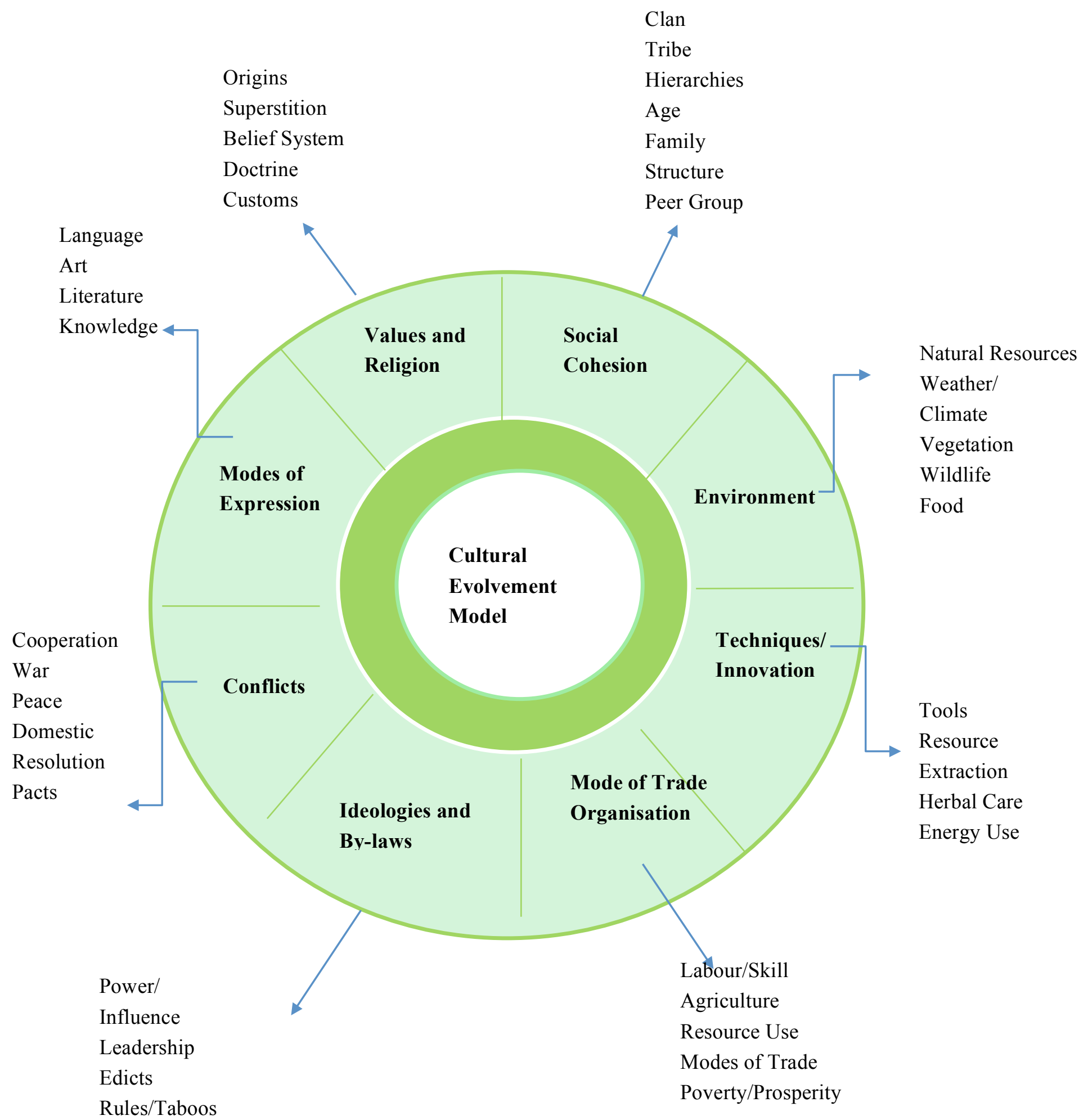

Rights

Tribal people, however, strangely attribute most of the events that occur in their environment to superstitious roots. David (2004) stated that cultural meanings are handled in, and are modified by, an interactive process used by people in dealing with phenomena that are encountered. To the scientists, culture is foreign elements behaviours that are parallel to methodical principles that sets the professional boundary is contributory to the admittance the culture of objectivity, transparency and respect for experiments as a valid object of research. But, 
understanding evolution and the ecosystem scientist, needs to study humanity in small clusters with similar values and ideologies. Cultural constructions such as the opposition of environment and society, and the separation of rationality from spirituality, the empirical science versus the religious symbols have provided science with its very foundations and still remains the reality of the scientific process. Notably, civilisation has transformed universal pattern of study using systematic analysis to derive reliable knowledge from objective reviews and observation. But indigenous and local communities through customary laws embedded with spiritual beliefs have ideated cultural knowledge for managing local ecology. Kumar (2017) explained that some of the simplest and most profound solutions for sustainability are found in cultures. Meggers (1954) reinforced that "the level to which a culture can develop is dependent on the agricultural potentiality of the environment it occupies." Gadgil et al (1995) underscored many parallels can be drawn from both the traditional ecological and scientific knowledge that is based on the observation and generalisation derived from observation and also attempts to render knowledge comprehensible to the human mind. "But different from scientific knowledge in being moral, ethnically-based, spiritual, intuitive and holistic"Sustainable use of natural resources and culture has an enduring relationship in contributing to the preservation of the environment and human subsistence. Pristine vegetation in most cases, communicates ethnic peoples' respect for cultural and ecosystem sanctity. Certainly, extensive urbanization and prevalent modern culture have decimated and in some cases subsumed tribal cultures or actuated their extinction. Many ethnic groups have proved to be demographically resilient, retaining unique identities while acculturating to the national society in the bid to preserve the natural ecology integrity in their domain. Culture as a dynamic process requiring supports as preconditions for development in a naturally progressive manner that must evolve internally. No event in human history has posed a prolong and evident threat to the fragility of human ecology than the menace of climate volatility. The emerging shortage of fresh drinking water, fertile vegetation and diverse ecological supplies amidst global development questions the validity of several systemic conclusions and calls the blending of approaches. The objective of synthesizing ageless bottom-up cross-cutting natural based solutions reinforces the enduring values of techniques that transcends several centuries of climatic volatility. This study promotes wholescale relevant cultural conversational integrationist approach that deepens sustainability, without supporting an unrestrained interactions of dominant cultures traditions.

\section{RELIGIOUS BELIEF, TRIBAL RITUALS FOOD PRODUCTION}

The knowledge of what human civilisation calls 'primitive' religion might be disintegrated and dissolve the scepticism of the intimate connection of early religions to food production. This necessitates the studying of tribal rituals in orienting and shaping other social practices (Gose1994). However, suggestions of archaeological findings appear that birth, death and food were of significance to early humans and the preoccupation with these, describe most of their behaviours. The worship of trees, plants and animals was probably an early manifestation of an important part of organised religion. Historically, animals although killed for food, were considered similar to man and the seasonal cycles of the death and rebirth of vegetation were thought to be related to the human life cycle. Human, and animals' fertility and vegetation luxuriance were obviously closely related. The Hindus believe that there is no obvious gap between animal and humans; animals, as well as humans, had souls that were continually passing between each other; all the species were interlinked in a whole web of reincarnation (Durant 1954). Gradual civilisation added new objects of worship like the sun, sky, earth, rain and other natural elements, specially ascribed the status of gods. Heiser (1981) believed that fertility rituals continued during the Roman Empire with untold excesses that culminated in the Roman decree abolishing their observance. It is also believed that "May Day" celebration was interlinked to the productivity of vegetation. Several ancient rituals linking agricultural evolution to cultural beliefs are still prevalent in the celebration of the 'New Yam Festival' amongst the eastern Nigeria Ibos till date. Nair (2016) submitted that the harmonious coexistence with nature abundantly reflects in a variety of tribal practices, belief systems, rituals, arts and literature. Numerous tribes are embedded with rich moral obligations to reverence elements that constitute ecosystems, for its continuous supply for future sustenance. These ethnic groups have an insightful conception of the natural ecosystems and time-tested wisdom for its vegetation productivity.

A brief summary of Thomas (1910) anthropological compilation of the Bini kingdom in Southern Nigeria, tell of the practice of protecting agriculture yields and soil fertility. 
'Ikhure' is carried out in the first month of the Bini calendar. The children of the reigning Oba sacrifice livestock to observe the festival of 'Ama' to mark the fertility of the soil and the welfare of crops. The indigenes had special idol known as Utu and a sacrifice (usually of a snail) is normally offered. Also, in some cases three (3) sticks, usually representing the first individuals who ever made farms along that road, are planted upright in the ground know as "Idiogbo" along the farm road. A sacrifice was routinely offered to them like other ancestors. In certain localities, women had an 'Ebo' called 'Ugiame 'or 'Igiame' representing the first women who ever went to cultivate a farm in its second year. This portrays a belief that an unseen force controls vegetation fertility and weather conditions. Numerous instances presuppose that rites related to the agricultural cycle were particularly scheduled to appease the gods during critical farming events like tiling of the soil and reaping of harvests.

For Indians Nair (2016), the cultural conservation of nature and wildlife is historically an ardent article of faith, reflected in daily lifestyle. It is believed that twenty-two centuries ago Emperor Ashoka decreed that it was a king's duty to protect wildlife and the trees of the forests. Historically evident edicts were inscribed on rocks and iron pillars across the kingdom, forbidding the destruction of forests and animal species. Also, Stone (1992) alleged that animals attained the status of gods, leading to the worship of cows, trees, insects, monkey, snakes, elephants etc., to reverence the unknown or out of sheer admiration. Heiser (1981) added that Buddha forty-five years of his lifetime in the forest was characterised by the significant events and individual trees that coincided with those events are still worshipped. Many Hindu gods and goddesses are shown to use animals as mounts. Farmers in Tanzania practised Wayyambuda, ancient tribal fertility rites where fields were sprinkled with medicine from seeds, blood and part of human bodies and the Aymaras in the highlands of Bolivia, sprinkle llama blood on newly planted potatoes in special festivals all for the assurance of bumper harvests.

In biblical history, key characters like Adam, Abraham, David occupation and the Christians in the days of Jesus Christ were predominantly agriculturalist. The bible is replete with scriptural verses using farming practices as illustration for spiritual guidance. The fertility of the land was sacrosanct and the success of the entire cultivation practice was dependent on divine intervention from God. Genesis 8.22 states thus, "And
Noah builded an altar unto the Lord; and took of every clean beast and of every clean fowl and offered burnt offering on the altar. And the Lord smelled a sweet savoir; and the Lord said in his heart, I will not again curse the ground any more for man's sake;" Leviticus 26:3-4 reading thus "If ye walk in my statutes and keep my commandment and do them; Then I will give you rain in due season and the land shall yield her increase and the trees of the field shall yield their fruit." Thanksgiving and worship were due to the God for multiplying their crops and flocks through feast like Passover, The Feast of Firstfruit, The Feast of Weeks etc., were all dedicated to God as proclamations and worship to God for a successful farming season and plenteous harvest.

In the Islamic Quran, Surah Hijr, ayat 22 says "And We send the winds fertilising, and cause water to descend from the sky, and give it you to drink. It is not ye who are the holders of the store thereof.". Surah Al-Baqarah, ayat 265 "And the likeness of those who spend their substance, seeking to please Allah and to strengthen their souls, is as a garden, high and fertile: heavy rain falls on it but makes it yield a double increase of harvest, and if it receives not Heavy rain, light moisture sufficeth it. Allah seeth well whatever ye do." all these and many more doctrines from unspecified religions captures linkages of agricultural practice with religious beliefs. This, however, negates earlier suppositions in other superstitions that correct observance of certain rituals will guarantee bumper harvests. Religious beliefs tackle environmental conservation on the principle that nature and its resources are created by God, and humans are entrusted with the responsibility of protecting it. Several professed the unity of all life on earth and the obligation of human beings to care for them. Whilst many of the traditional cultural conservational rituals might have been mere subsistence tactics and not sufficient for sustainable resource management, a broader ecological insight suitable for sustainable development planning and biodiversity conservation can be extracted through deeper assessment. Nonetheless, ethnic cultures believed the sustainability of their natural resources has direct linkages to the spiritual integrity of their sacred sites

\section{CULTURE, AGRICULTURE AND CLIMATE CHANGE}

Disruption and rapid change in the social values increase vulnerability to emotional disorder that could spark antisocial behaviour and communal tension. Cultures are dynamic with capabilities to subtly 
accommodate metamorphosis especially if initiated by ethnic people themselves. With the structural weaknesses for managing and adapting to complex climate volatility, external pressures and unproven values burden natural synthesis and distort the liberty to control customs, beliefs and subsistence. While interface with dominant cultures adulterates social patterns and belief system and rich agricultural knowledge that successfully equilibrated nature. But traditions need not be drastically provoked when reforms are introduced through careful considerations of the capacity to collaboratively evolve. The dynamics of human society is therefore complex but seems to link with ethnography, beliefs and the evolution of Agriculture. Historically interpreting human belief in ancient cultures revealed that traditional sacrifices and offerings were presented to appease deities for fruitful harvest by preventing evils or calamities. Yet modern sciences have discovered extreme weather conditions to cause disruptions of social structures and livelihood sources.

Citing P. Mapfumo et al (2012) research on Makoni and Wedza district in Zimbabwe explains climate variability causes. $40 \%$ of respondents in Makoni attributed weather patterns variations to natural causes, either because of effects of dwindling rainfall on water basins; spiritual-the will of God; or the result of unexplained factors. Many were convinced that climate was changing, approximately $35 \%$ could not align the perceived changes with any external force, $30 \%$ assumed weather fluctuation were being caused by unexplained natural forces. More than $20 \%$ believed that cultural forces, which included disrespect of traditional sacred places like prayer shrines and mermaid pools in local rivers, rise in Christianity, random cutting down of customary sacred trees, non-performance of rain-making ceremonies, among other cultural beliefs, were the root causes of low rainfall and droughts. This is contrary to the logical testability and objectivity of natural science that make arrive at conclusions from purposive methodologies. Relatedly, Nair (2016) emphasized that the lifestyle of the tribal people of Indian are enshrined in myths, folklore, religion and arts, that attribute supernatural powers to plants, animals, water bodies, mountains, the wind, sun and moon, revering nature for continuous supply.

Heiser (1981) opined that deploying animals to cultivate farmland has increased the cultivated areas which in turn may have led to increased erosion. The passion to plant more arable lands has heightened contentions amongst tribal clan, just as communal conflicts are known to stimulate scarcity and deprivation. Yet agrarian settlements have imbibed tolerance to prevent conflicts and engender harmony amongst pastoralists, cultivators and other parties. Co-habitation and ensuing understanding provide opportunities for researching the cultures and the biology of animals. Dwindling climatic conditions have mostly been responsible for desert encroachment and environmental desiccation from ancient times. But industrialisation has resulted to massive exploration of natural resources that is grossly responsible for the mismanagement of agricultural. Also, the distortion of the environment from growing human population and urbanisation. Gordon (1936) maintained that societies have subliminal progressive and conservative tendencies, self-destruct and re-creative abilities for triggering new environmental paradigm by including elements of social change. This is because the degradation process was gradual but never catastrophic. Rainfall unpredictability devastating several regions with droughts or excessive flooding is detrimental plant and animal life at the expense of dominant societal elements. Nonetheless, several beliefs systems known to have prudently managed its natural capital survived against dominant values without losing its cultural norms. Ancient wisdom was documented for forthcoming generations through diligence to preserve a better future for themselves and as early ecological knowledge vanguard, the preservation of values and techniques is proprietary that is beneficial to global developmental policies. The condensed repository of proven experiences transiting generational non-systematically makes the vast body of knowledge unsearchable to strangers and heritages that are disinterested in its continuity.

\section{Figure 2. Tribal People Perception Natural Environment}

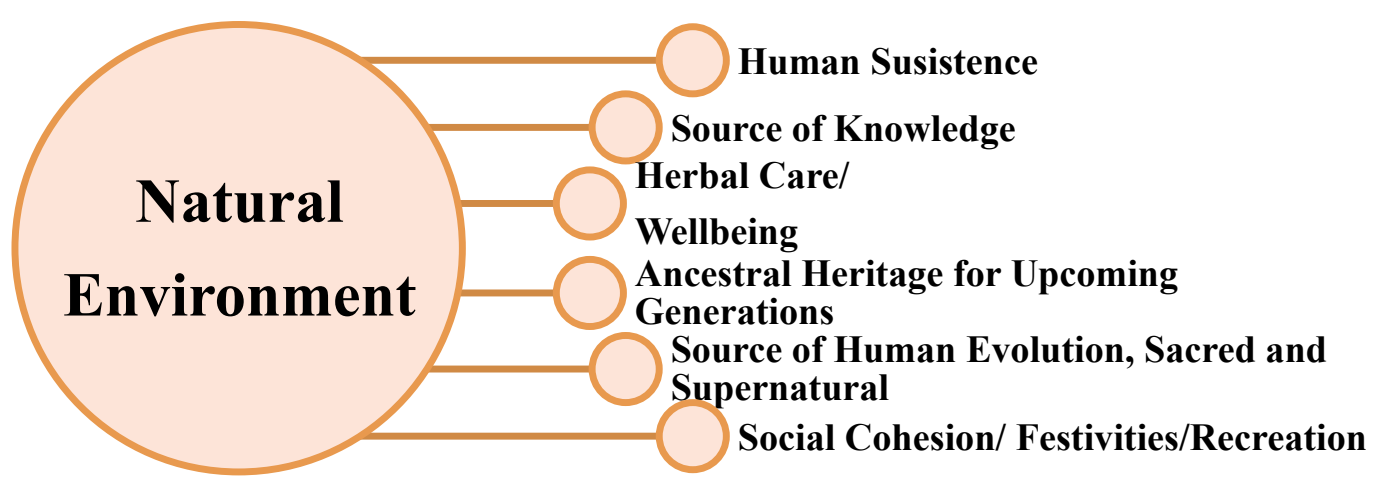




\section{TRIBAL CONSERVATION KNOWLEDGE, INSTITUTIONAL PROTECTION AND SUSTAINABILITY}

Tribal wealth tied to vegetation fertility runs an organized and resilient subsistent system focused on the efficient consumption of ecological resources. Rural economic dynamics without organized dataset cannot concisely reflect household wealth that primarily centred on natural resource management, knowledge and a common sharing system. Chambers and Conway (1991) defined livelihood to "comprise people, their capabilities and means of living including food income and assets." Household livelihoods are therefore mostly centred on informal exchanges, social behaviours and joint equity on a common resource stock. WCED (1987) surmised that ownership of land, livestock, trees, rights to grazing fishing, hunting or gathering can enhance households' sustainable security of livelihood. But actual worth of rural households' wealth can be valued through deeper ethnographic study. Rural asset however, is constrained by ecosystem devastation, ecosystem resource harvest restrictions and the fragile social infrastructures that disrupt farm yields linkages to markets.

The entirety of cultural conservation knowledge is beyond providing conditions for tribal groups to control the pace and manner of adjustment to the global society, it's about safeguarding the future. The IUCN as the largest network that harnesses scientific knowledge, in addition to ethnic peoples' traditional knowledge for conservation, apply resolutions to protect diverse cultural and socioeconomic lifestyles in natural habitants. Moreover, recognising the inherent dignity and inalienable rights of individual human family members as the foundation of freedom, justice, and peace, the 1948 universal declaration ascertains the economic, social, and cultural rights of everyone. This is in addition to the principles of international cultural cooperation that instils cross-cultural knowledge through enriching the cultural life in member-nations through the establishment of mutually beneficial, peaceful and lasting relationships. Rio Principle 22 emphasized the "vital role of indigenous people and their communities and other local communities" in sustainably managing the environment with their knowledge repository and traditional practices. Thus it recommended sovereignties to "recognize and duly support their identity, culture and interests and enable their effective participation in the achievement of sustainable development."
Living organisms are sustained by its source, that is dependent on replenishment for continued existence. Safina (2011) stressed that the message of a century and a half of biology and ecology is life, which more than anything depends on relationships among energy, land, water, air, time and various living things. Humanity is eternally in a complexity encompassing all living things, energy and non-living matter that flows through living, beyond human-to-human interaction or spiritual interaction. This pragmatic and rational human practice geared towards the preservation of natural resources and endowments is developed and acquired through lifelong self understanding assessment expanded by attentive trials and experiential reasoning of ancestral knowledge. It understands the sublime traditional linkages to the ecosystem that harness the power of the natural process for human benefit, transmitted through informal apprenticeship revolving round social interaction and real life experiences. Recognizing knowledge evolution is an ageless human activity that enhances peoples' capability for efficient natural resources consumption, institutional support reinforces their stewardship of conservational initiatives.

Levi-Strauss discovered in (Conklin, 1954) exposition of the Hanunoo people, that indigenous knowledge evolvement is akin to intellectual application and methods of observation in science with respect to their extreme understanding of biomes and the concentration on precise knowledge. Sillitoe (1998) citing Reyna (1994), argued that juxtaposing indigenous and scientific perspectives is not intended to translate cultural conceptions into scientific discourse or necessarily evaluate them according to its values. Both exhibits certain peculiarities, scientists may revise their perceptions regarding objectivity, positivism, reductionism, etc., to accommodate the views of others. This is because majority of them desire intimate familiarity with local plants and precise knowledge. The Hanunoo people specially classified all forms of local varieties into seventy-five categories and distinguish about a dozen kinds of snakes, sixty rare species of fish, more than a dozen types of fresh and saltwater crustaceans. The thousands of insect present are grouped into a hundred and eight named kinds, including thirteen for ants and termites. Four distinct types of leeches are distinguished. Altogether 461 animal types are recorded.

In a study by Deikumah et al (2015), the Akan tribe, designed a taxonomy for local bird species following scientific methods. Over 143 species belonging to 44 families were correctly 
identified in local Akan dialect, using "plumage, vocalisation or behavioural characteristics and belief system of the people". Bartle (2007) featured that an extensive survey conducted on herbs used by Ghanaian herbalist revealed that 20 percent had no medical indications, but were mere 'placebos' for patients' optimism, 40 percent were 'hallucinogenic' that persuaded patients of the attraction of mystical powers to fight ailments. Another 40 percent were genuine in scientific interpretation indicative of medical results, even though, the hope provided by placebos and hallucinogenic schemes increased recovery chances from boosted confidence. Traditional keepers as dispensers of local ecological knowledge and wisdom are typically select elders in unique cultural formations with piles of proprietary knowledge that are almost lost to civilization for lack of documentary evidence. This results in misrepresenting tribal knowledge as fallacious, therefore repackaging intellectual discourse to include the knowledge channel of five human sense organs of sight, smell, taste touch, and sound (Sillitoe 1998). The ability of farmers to test soil composition or acidity by feeling soil texture, smelling or tasting can unveil rich undated local intellectual discourse through applied indigenous knowledge. Collaborating with ethnic cultures for effective and sustainable development is an imminent concept for pragmatism.

Given the fundamental significance of cultural economic patterns and considering the extreme contrasts between tribal and national economies, the economic linkages of tribal propriety information with markets is critical. A tribal culture may surrender part of its autonomy, but can still continue to be ethnically distinct through its tested and applied knowledge if allowed to retain its values that remains unexploited by outsiders (Bodley,1975). But respect for tribal cultural sanctity is complex due to vulnerability to politics and instituted powers, citing the 'shamanistic' example, whose activities were particularly frustrating for Soviet authorities over continued efforts to regulate the tribal resource exploitation practices by instructing hunting and fishing on certain days and prohibiting the killing of specific animal species. Yet ethnic minorities have distinct set of rights linked to their social, political, and economic situation as ancestral stewards for conservation of valuable lands and resources. Operationalizing international provisions through the acknowledgement of national policy frameworks is a significant survival factor, that bolster ethnic communities to withstand possible climatic catastrophe.

\section{CASE STUDIES: CULTURAL ENDOWMENTS, CUSTOMS AND ENVIRONMENTALISM}

Climate change is a long-term threat to humankind as well as, a short-to-medium-term threat to the natural ecosystem globally. Systematic climate policies must cognise the subtleties of ethnic cultures and its vast repository for cataloguing natural species, future prospects and threats in resolving of the international climate complexities. An institutionally coordinated bottom-up and home-grown emission reduction structure to reinforce the comprehensive interventions and multi-country policy peer review system is now mandatory. This is especially when contextual tribal ecological practices see species and vegetation as resources for sustenance and development that should be preserved for human sustainability. Case studies highlighted in this paper reflects a purposive ancestral knowledge that expresses that consumption of natural resources can be efficient and concurrent with the preservation of nature if developmental goals troubleshoot the root causes of environmental metamorphosis. Therefore, institutionalising cultural conservational knowledge is a sustainable pathway of reconciling environmental resources, the inexhaustible cultural knowledge and economic goals. Systematic attempts at mainstreaming series of the traditional practices reinforces the notion that some cultural lifestyles of tribal people have proven to have prudently managed the natural ecosystem prehistorically.

\subsection{CASE STUDY ONE}

The World Bank 2004 highlights of 27 ethnic council of elders in Jalapa, Mexico described that community members are united by a common origin and spirituality anchored on love and reverence for nature. Shared hands-on knowledge tied to customs acknowledges local elders as custodian of historic cultural conservational knowledge. Sacred geographical properties like waterways, caves and islands, within the territories are protected but admonishes humanity to mutually preserve nature, avoiding water and air pollution, deforestation and the indiscriminate exploitation of resources. Acknowledging learning as a lifelong journey; starting from parents and community elders. Language serves as instrumental channel that reflects the spirit of cultures. It also emphasizes the significance of harmonious-existence with lands and territories for human survival. Plants and animals as food and medication should be preserved and respected by authorities and non- 
indigenes. Gender equality and the dignity of grandmothers, mothers, and sisters, represent life and the sustainability of their communities. However, concerns of institutionalized educational systems that negates cultural history for enriching local education through dissemination of ancestral experiences and knowledge abounds.

\subsection{CASE STUDY TWO}

Acheampong (2010) stressed the effects of cultural sustainability of some ethnic people of Ghana on the local ecosystem using strictures and taboos to safeguard the misuse of water bodies, land and forest formation. In a majority Akan ethnic group, water bodies are associated with the Abosom (god) and are efficiently utilised in accordance with the dictates of oracles as directed by its priests. Customary laws also mandate the preserving of lakes and rivers as the sanctuary of the revered Abosom. This ancestral practice of conserving water bodies prevents water-borne diseases because it allows bathing, swimming and cleaning of domestic animals in the downstream to prevent pollution in the designated upstream for drinking and domestic chores. Households are deliberately located at a distance from rivers or lakes to prevent contamination from household waste and spread of water-borne diseases, whilst the laborious journey to water source encourages efficient domestic consumption. The superstitious belief 'to enable the sea goddess bond with other sea creatures, believed to be her offspring' forbade fishing on Tuesdays and certain period, accelerates fingerings preservation to maturity. Certain fish species alleged as treasured offspring of the sea goddess were forbidden and rejected if erroneously harvested ultimately replenished fish stock. These practices were also extended to other ethnic groups along the forest zones, who forbade hunting and farming on certain days and periods annually. Hunting or killing young, pregnant or nursing games for consumption was a taboo. These unconventional cultural beliefs promotes the sustainability of lives on land and water by preventing overharvesting and the extinction of rare species.

\subsection{CASE STUDY THREE}

In this vein, Drani (2015) submission on the Empaako cultural practices Batooro, Banyoro, Banyabindi, Batuku and Batagwenda ethnic groups in western Uganda, underlines the celebration of social identity as a precursor of unity, peace and reconciliation. During the child naming, extended family are gathered to comprehend the source of ancestral values. The ceremony often supervised by a clan head, requires that a paternal aunt first confirm the baby's parentage by examining the body features and resemblance to relatives. Once confirmed, the clan head declares one of the twelve names presented, before gifts including prominently a culturally hallowed tree seedling to the baby to signify new life. The tree is expected to be planted in baby's honour. This culture improves the tree count in the community and preserves local vegetation.

Relatedly, Ann-Elise Lewallen, writes that the Ainu Indigenous people of Hokkaido in Japan and their ancestors are incredibly resourceful and creative in surviving with resources at their disposal. Connecting with the roots literarily bonding with trees, plants, and the biological life around them. She narrates that the interactive and reciprocal relationships the people developed with the waterways, forests, and mountains of Hokkaido-the second largest island in Japan's archipelago, have been key to the evolution of their cultural practices. The United Nations conference (2014) on indigenous people reported diverse cultural techniques for preservation of natural resources stock. It cited the indigenous people of Australia known to have historically applied customary burning practices in managing the savannah regions. Annual uncontrolled wild and hot fires dry seasons were common practices. Experiences in northern region revealed strategic reintroduction of traditional patchwork burning early in the dry season can limit the scale and intensity of late dry season fires; reducing emissions of greenhouse gases and also allowing the peoples to generate sustainable livelihoods through the carbon exchange. Articulação Pacari, (2012 UNDP Equator Prize recipients), mobilized herbal plant producers and local health practitioners to establish sustainable harvesting techniques as self-regulating control of plant quantity, safety and sanitary conditions. In the absence of legislative framework, these traditional herbal care operators and community-based organizations preserve the cultivation of medicinal plants, traditional ecological knowledge and protect biodiversity in Brazil's savannah ecosystem.

\section{TRIBAL KNOWLEDGE AND SUSTAINABILITY PRAGMATISM}

Reappraising and emulating these cultural practices can easily stimulate the unification of social diversity, jointly connect humanity to ethnic groups inherent virtues and weaken natural borders. Intricate intercultural exchange diffuses social influences beyond boundaries to foster common homogeneity. 
Electronic media broadcasting multicultural values have accelerated shrinking global events into handheld devices and LCD screens. This amplifies isolated developmental challenges like poverty, flash-floods, hurricane, diseases etc., into intercontinental dimensions. Humanity spontaneously sympathises a globalised values system that esteem freedom, equity, solidarity, sustainability etc., thereby coalescing diversified cultural sensitivities into developmental outlook. Cultural globalisation encourages culture blending, clearly defining tolerable protocols to diverse parties. Ideas, attitudes and values transcending local cultural beliefs and lifestyles are reconfiguring the perceptions and aspirations of modern society. Culture both as an enabler and driver of socioeconomic interconnectedness can also homogenize cultural conservational expertise that represent the universality of diversity. Ban Ki-Moon (2015) referred to culture as an integral part of global development, stating that complete ownership of development strategies demands the full integration of culture and all must laboriously ensure that culture, heritage and religious diversity should not promote conflicts nor perpetuate injustice.

The footprints of multinational developmental agencies and transnational corporations engendering inclusive operational environment reflects the inherent heterogenic linkages that policies can coax for human development. Proper recognition of stakeholders rights in pluralism that equitably shares accrued benefits of the natural resource pool and wealth of diversity can enhance cross-cutting development. Mainstreaming tribal conservational knowledge can be relevant to systematically harness the traditional and territorial practices that sustainably define economic and social aspect of trade and troubleshoot social challenges. Sustainable ecosystem depends on enduring cultures and the disintegration of ethnic cultures (that lays the groundwork for sustainable future), directly impinge everything else. Nonetheless, developmental setbacks like geopolitics, extremism, poverty, mass migration, disease, is dimensionally dissolving historical and sociocultural sovereignties. The need for societal understanding and collaboration requires that entities must subtly emphasize the variables that appreciate divergent disposition in continually shrinking ecosystem. International pressure and advocacy groups can find strategies to lobby better entitlements, humane cultural and sentient ecological factors.
An exhaustive traditions and cultural patterns sensitivity promotes the sustainable use of local resources and sociocultural wealth that evolves into the mainstream culture. If conservation is 'the management of human use of vegetation for sustainable benefit to this generation and maintaining future generations potentials to meet its needs, the IUCN SCOPE will be constrained performing its core scientific mandates if social and behavioural impact on the natural environment are not captured. Commonalities, divergence and analysis of interest discloses some of the most fundamental features in international treaties and agreements for diplomatic interface and in-road into other cultures. Nations constitutionally defines its cultural exclusivity by encapsulating its history, language, religion, philosophy, legislation, power structure, and general way of life in statutory document. The process of ratifying treaties implies certain levels of bargain and compromise, the pacts or commitments requires parties to disclose the propositions and preoccupations in addition to sensitivities, values and concerns. The skilful crafting of the intricacies of the Paris climate change agreement, suggests a tacit affirmation of culture as a precursor to the success of the exercise and an historic signing enriched and deepened a multidimensional lowcarbon programme that successfully assuaged the sensitivities of the 195 signatory culturally exclusive countries.

This paper therefore, reviews tested cultural techniques that confront the common challenge of preserving the universal commonwealth, as acceptable phenomenon that supports openmindedness and inclusivity to bridge the borderlines of customs and civilization. Human actions as organic processes of natural resources, beliefs and economic inclinations, demand cautious appraisal of values and traditions to differentiate empirical science from fiction. Definitely, many environmental decisions require experimental testability for validation, through objectivity of structure and sub-structures that provide technical guidelines and periodic assessment. Also, knowing that communities' elders are typically the traditional keepers of local knowledge and wisdom, local farmers' behaviours, also as knowledge user could be shaped by cultural biotic and abiotic factors. Presenting superior arguments on the concept of climate change and cultural beliefs should be respectful of their beliefs, dignity, integrity and apprehensions. Scientific undertakings and inclusive developmental programmes should acknowledge indigenous knowledge as robust source of food production and herbal care that have supported generations for centuries. 


\section{CONCLUSION: HOW CULTURAL CONSERVATIONAL KNOWLEDGE CAN CONTRIBUTE TO SUSTAINABILITY}

The global economy fuelled by consumerism, population surge, insecurity and geopolitics is consistently aggregating, and has necessitated the emphasis on efficient resource consumption. To forestall recent generations grave and wasteful opportunities, individual as beneficiaries of the resource commonwealth with attendant carbon footprints should take a stand on the existing climatic calamities and the danger it portends. However, the immediate preoccupation should be to provide guidance and choices for accountable decisions and symbiotic outcome for all and sundry. Organising multidimensional policies in environmental decision pipeline contains complex questions to which only natural science cannot resolve. Institutional structures that leverage inclusive, coordinated and reconciled decisions are calibrated to strengthen SDGs, needs to delve beyond the substructures for ageless proven conservational practices. Underplaying the significance of cultural conversation knowledge in combating sustainability threats is akin to obliterating centuries of condensed human intelligence that predates modern civilisation. Series of retrogressive cultures infringing on civilisations are being flagged, modified or abolished in support of human development. Nonetheless, collaborating with ethnic cultures for effective governance and sustainable development is an enduring concept of pragmatism.

For example, the Olympics was ancient Greek culture that has evolved to the present global outlook. Penn Museum recounted that the ancient Olympics termed after Mount Olympos was primarily a part of the Zeus religious festivities for city-states of the Greek world. The Olympics which started from Athens in 1896, has experienced transformations from the Olympics Oath to the Olympics Torch to accommodate the sensitivities of participating nations in the post-1894 modern competition. This globalisation of the original Greek culture

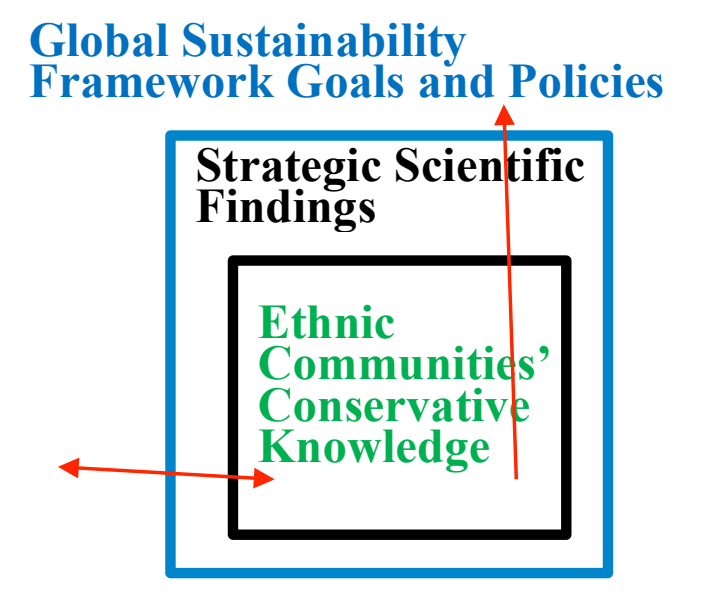

has entrenched global peace and unity to bring social and cultural renaissance. Ball (1985) submitted that the modernisation of the Egyptian and Babylonian numerical values written on papyrus and clay slates by the early Greeks and Roman philosophers was achieved by questioning the "how" and "why" of other cultures. The advancement of the discovery resulted in understanding the theory of numbers and extensive higher analysis that generated further breakthrough in potentialities of mathematical calculations like kinematics, theoretical statistics, dynamics, astronomy etc. Simple symbols have metamorphosed to fundamental mathematical language for solving physical global problems and revolutionising science and technology. Likewise, Nweke (2006) citing (Okigbo 1980), submitted that Cassava, a major staple for rural and urban poor in Sub Sahara Africa, was introduced by Portuguese traders to Africa from Brazil in the 16th century as a 'famine-reserve crop'. Millet, banana and yam were the traditional staples in the Congo where the crop was first cultivated, farmers effortlessly adopted the crop because of its dependability as food source during droughts and during periods when soil degradation or deforestation exacerbates soil fertility. FAO 2002 data reported that Nigeria currently cultivates 34 million metric tonnes annually as leading producers of cassava globally.

A great deal of traditional knowledge, including customary laws and folklore, has been undermined and destroyed by colonists and postcolonial legislations that imposed dominant statutes and values. The has threatened the extinction of tribal cultures on many fronts, largely arising from the exclusion decision-making frameworks because perceived backwardness of beliefs. Yet, sustainability can only thrive when humankinds believes in the uniformity of its future benefits, because the real challenge of humanity is to foster growth in sustainability. As illustrated in figure 3, it would be valuable for natural and social scientists to collaboratively study the ingenious tribal people as natural biodiversity stewards that have survived hash and complex environment, with the ecological resource base intact.

Figure 3. Knowledge Transition Process 
Case studies highlighted in this paper shows linkages of religions and the existence of vegetation productivity that transcend the natural. Reverences to unseen forces guide the consumption of natural resources stock. Summarily;

- Community people dedicate themselves to study the knowledge of natural environment through practices, examination, informal apprenticeship and social interactions.

- The tribal people perceive their progenitors as original owners of natural ecosystem and the resources therein are bequeathed to them as stewards. Divinised oracles guides consumption pattern (See Figure 2). The ancestral priest ascribes the judicious usage as reverence to certain belief system. Hence, food cultivation and fertility of vegetation is through the natural process tele-guided adherence to the instructions of ancestors.

- Tribal cultures appreciate nature as source of life and as enabler of continual supply of sustenance and livelihoods for the present generation and an heritage for future generation.

- Traditional conservative knowledge is the result of an agelong thorough process of informal but intelligent collation of methods and apprenticeship, over several ancestries on cultivating crops and herding animals to withstand diverse weather conditions.

- There is also a growing value of tribal conservational knowledge as beneficial to human civilisation and global development. Several commonly used ancient techniques like drought-resistant crops, soil replenishment, herbal remedies, food preservation have provided a base for further advancement of modern technologies.

Conclusively, the development process could be more inclusive when perspectives in the foregoing are incorporated into programmes that directly impact ethnic communities. Additionally, the wealth of tribal knowledge can be explored for solution or territorial specific to species as first-line measures. The repository of undocumented data transcending generations and equally preserved cultural autonomies can serve as resourceful and dependent partners. Also protecting tribal people to safeguard local subsistence amidst complex weather conditions techniques through interventions that involve stakeholder consultation. This identifies developmental priorities using community-driven problem analysis that are sensitive to cultural values and dignity. Strengthening weak social systems, therefore, requires the institutionalising validated discoveries as a strategy to accelerate knowledge diffusion amongst different social groups and proffer easily organised small-scale solutions across several fronts during severe weather condition. Formal education curriculums in rural settings should gradually incorporate local customs and history to curb illiteracy and enrich cultural regeneration. A new breed of local people that coalesce traditional knowledge with logical consistent sciences will create a hybrid generation of more efficient and far knowledgeable people. Electronic and print media can further provide key supports in updating realtime weather reports; alerts for preparedness for any eventualities; awareness building and latest beneficial agricultural innovations. Therefore, using collaborative mechanisms as shown in figure 3 above allows a two-way free flow of knowledge that deepens mutual trust and respect for knowledge linkages as double-edge propositions.

\section{REFERENCES}

1. Acheampong E. A. (2010) The Role Of Ghanaian Culture And Tradition In Environmental Sustainability November 10, Https:/www.Modernghana.Com/News/306123/1/TheRole-Of-Ghanaian-Culture-And-Tradition-In-Envi.Html Green Ghana Foundation

2. Agrawal A., and Clark C. Gibson (2010) Communities and the Environment: Ethnicity, Gender and the State in Community Based Conservation; Rutgers University Press, Psicataway, USA

3. Andrew J. Hoffman 2010: Climate Change as a Cultural and Behavioural Issue, Elsevier Inc.

4. Anad R.P. (1981) Cultural Factors in international Relations, New Delhi, Abhinav Publications.

5. Ball, W. W. Rouse. A Short Account of the History of Mathematics. Dover Publications Inc. Mineloa, N.Y. 1985

6. Bartle P., (2007), Studies Among the Akan People of West Africa Community, Society, History, Culture; With Special Focus on Kwawu. Accessed online www.cec.ven.bc.ca/cmp on 19 February 2018

7. Bodley, J.H. (2008), Victims of Progress Alta Mira Press $5^{\text {th }} \quad$ Ed $\quad$ ISBN-13:978-0-7591-1148-6 Pp $\quad 157$ Lanham

8. Braidwood R. J., Halet Cambel and Will Schirmer, 1981: Beginnings of Village Farming Communities in Southeastern Turkey Canyonu Tepesi 1978 and 1979: Tailor and Francis Ltd Vol 8. No 3, 
9. Deikumah J., Konadu V.A., Kwafo R., (2015), Bird Naming Systems by Akan People in Ghana Follow Scientific Nomenclature with Potential for Conservation Monitoring. Journal of Ethnobiology and Ethnomedicine, DOI10.1186/s 13002-015-0062-y

10. Drani E., (2015), Enhancing The Visibility Of Intangible Cultural Heritage: The Empaako Traditional Naming Practice In Uganda http://www.ichngoforum.org/theempaako-traditional-naming-practice-in-uganda/ The Cross-Cultural Foundation of Uganda November 13

11. Durant W, (1954), Our Oriental Heritage, New York: Simon \& Schuster

12. Falkner R. (2016), The Paris Agreement and the new logic of international climate politics

13. policy experimentation at national level, London School of Economics and Political Science International Affairs 92(5), pp. 1107-1125.

14. Feike Sijbesma (2016), Our Minds are wired to fear only short-term threats. We need to escape this trap. World Economic Forum Global Agenda www.weforum.org, June 2016

15. Food, Agriculture Organisation of the UN FAO, Rome, 2015, State of Food Security in the World

16. Gadgil M., Folke C., Berkes F., (1995) Traditional Ecological Knowledge, Biodiversity, Resilience and Sustainability, PP 269-289 Dordrecht, Kluwer Publishers

17. Hofstede, G. (1997). Cultures and Organisations: Software of the mind. New York: McGraw Hill.

18. Kanowski, P. J. and Williams, K. J. H. 2009. The reality of imagination: integrating the material and cultural values of old forests. Forest Ecology and Management, 258 (4): 341-346

19. Levi-Strauss, C., (1962), La pense'e sauvage. Librairie Plon, Paris [English translation (1966) The Savage Mind, University of Chicago Press, Chicago, IL].
20. Lessons about conservation from the Indigenous Ainu of Japan Dylan Ruan, Living Lab Intern, UCSB Sustainability http://www.sustainability.ucsb.edu/lessons-aboutconservation-from-the-indigenous-ainu-of-japan/

21. MEGGERS B. J. (1954), Environmental Limitation on the Development of Culture. American Anthropologist 56:80124.

22. Mtambanengwe, F., Mapfumo, P., Chikowo R., Chamboko T., (2012), Climate Change and Variability: Smallholder Farming Communities in Zimbabwe Portray a Varied Understanding African Crop Science Journal, Vol. 20.

23. Nair S. M., (2017), Cultural Traditions of Nature Conservation In India Accessed online on 23 December from http://ccrtindia.gov.in/readingroom/nscd/ch/ch11.php

24. Nweke I. F., (2006), The Cassava Transformation, FAO http://www.fao.org/docrep/009/a0154e/A0154E02.HTM accessed on 12 January 2018

25. Penn Museum, The Game https://www.penn.museum/sites/olympics/olympicorigins.s html Pennsylvania

26. Sillitoe, P., (1998) The Development of Indigenous Knowledge: a New Applied Anthropology, Curr. Anthropol., 39, 223-252.

27. Thematic Paper towards the preparation of the 2014 World Conference on Indigenous Peoples http:/www.un.org/en/ga/president/68/pdf/wcip/IASG\%20 Thematic\%20Paper_\%20Traditional\%20Knowledge $\% 20$ \%20rev1.pdf

28. UNCTAD Report (2015), The role of Smallholder Farmers in Sustainable Commodities Production and Trade, TD/B/62/9, 30 July

29. UN Human Right: Realising the Rights of Development; 2013, HR/PUB/12/4, UN Publication

30. UN World Summit on Sustainable Development (September 2002),

$\mathrm{UN}$ 